T H E O L O G I A V I A T O R U M 



\title{
THEOLOGIA VIATORUM
}

\author{
Jahrbuch \\ der \\ Kirchlichen Hochschule Berlin
}

$1948 / 49$

\author{
Herausgegeben \\ im Auftrage des Dozentenkollegiums \\ von \\ Dr. Erwin Reisner
}

WALTER DE GRUYTER \& CO. / BERLIN

vormals G. J. Göschen'eche Verlagshandlung / J. Guttentag, Verlagsbuchbandlung / Georg Reimer / Karl J. Trübner / Veit \& Comp. 
Drudk: H. Wigankow, Berlin 